\title{
SELF DOUBLE EMULSIFYING DRUG DELIVERY SYSTEM (SDEDDS): A REVIEW
}

\author{
Padole Atul*, Bodhankar Mitali \\ Gurunanak College of Pharmacy, Nagpur University, Nagpur, India-440026 \\ *Corresponding Author's Email: atulpadole05@gmail.com, mit21_bod@yahoo.co.in
}

Received 27 Sep 2012; Review Completed 31 Oct 2012; Accepted 01 Nov 2012, Available online 15 Nov 2012

\begin{abstract}
:
Self emulsifying drug delivery systems (SEDDS) are well known for its potential to improve the aqueous solubility and oral absorption of lipophilic drugs. Self double-emulsifying drug delivery system (SDEDDS) are basically used for drugs having low solubility in water, but its potential application for the drugs defined as "high solubility low permeability class" or a biopharmaceutical classification system [BCS] class III drug is appreciable, in which gastrointestinal permeation is the rate controlling step in the absorption process. The most important factor affecting the oral absorption of a drug, besides dissolution, is the permeability of the drug across the gastrointestinal lining. Improving permeability may, therefore, potentially improve the bioavailability of a drug. In this review we discuss the preparation, stability, formulation and characterization of SDEDDS. Key Words: Multiple emulsion, self emulsifying, Protein peptide drug delivery, High soluble poorly permeable drugs.
\end{abstract}

\section{INTRODUCTION:}

Many drugs are delivered orally as it is the most favorable route of drug administration. Nevertheless, many potential hydrophilic drugs such as protein and peptide drugs administrated orally exhibit low oral bioavailability mainly due to their low intestinal permeability. For such kind of drugs defined as "high solubility low permeability class" or a biopharmaceutical classification system [BCS] class III drug, gastrointestinal permeation is the rate controlling step in the absorption process ${ }^{1}$. Transport of hydrophilic drugs across the intestinal epithelium is confined mainly to paracellular pathways. However, the limited surface area and the tight junctions present between the adjacent cells restrict the transport of the drugs and are responsible for the low bioavailability of hydrophilic drugs across the paracellular route. The small oil globules are absorbed through lymphatic system their by bypass portal circulation and hepatic first pass effect.

Also the drugs which undergo hepatic first pass effect have low bioavailability which can be improved by absorption and transport through lymphatic system. Many approaches such as absorption enhancers ${ }^{2}$, chemical modifications ${ }^{3}$ and pharmaceutical means were used to enhance oral bioavailability of those drugs. Among these approaches, water-in-oil-in-water emulsions show great potential for enhancing oral bioavailability of BCS class III drugs $\mathrm{s}^{4,5}$.

The majority of orally administered drugs gain access to the systemic circulation by direct absorption into the portal blood. However, highly lipophilic compounds may reach the systemic blood circulation via the intestinal lymphatic system. This alternative lymphatic absorption pathway from the gastrointestinal tract (GIT) has been shown to be a significant contributor to the overall bioavailability.

SDEDDS are poly dispersed systems where the dispersed phase contains the droplets of the continuous phase. These double emulsions are of two types: W/O/W types multiple emulsions and O/W/O types multiple emulsions ${ }^{6}$. Small water droplets are dispersed in bigger oil droplets and these oil droplets are again dispersed in continuous aqueous phases ${ }^{7}$, Similarly in O/W/O type multiple emulsions, small oil droplets are dispersed in larger aqueous droplet and these aqueous droplets are again dispersed in continuous oil phase. Their potential pharmaceutical applications include uses such as taste masking, adjuvant vaccines and an immobilization of enzymes, sorbent reservoir of overdose treatments and for enhancement of enteral or dermal absorption ${ }^{8}$. Multiple emulsions have been formulated as cosmetics, such as skin moisturizer. Prolonged release can also be obtained by means of multiple structures. These systems have some advantages, such as the protection of the entrapped substances and the incorporation of several actives in the different compartments. Despite their potential usefulness, applications of multiple emulsions have been limited because of thermodynamic instability and their complex structure $^{9}$. The basic rationale for the use of $\mathrm{W} / \mathrm{O} / \mathrm{W}$ and $\mathrm{O} / \mathrm{W} / \mathrm{O}$ type multiple emulsions as means of prolonged delivery of drugs is that the drug contained in the innermost phase of forced to partition itself through several phases prior to release at the absorption site ${ }^{10}$. Thus the partition and diffusion coefficient of the drug and the strength of the middle membrane phase, which is a multi molecular layer of oil, water, and emulsifier molecules at both the interfaces of multiple emulsion system, control the drug release from these systems ${ }^{11}$. Although multiple emulsions are still infrequently used, their potential applications are numerous and the investigation of these systems is now an active field research, especially in such product areas as pharmaceutical drug delivery systems, cosmetics and foods $^{12}$.

Approaches to improve the bioavailability of BCS Class III drugs are:

$>$ Permeation enhancers

$>$ Prodrug

$>$ Chemical modification

$>$ Pharmaceutical means

$>$ Multiple / Double emulsions 


\section{COMPOSITION OF SDEDDS:}

The self double emulsifying process is depends on

- Emulsification equipment

- Nature of the aqueous phase

- Nature of the oil phase

- Volume of dispersed phase

- Nature and quantity of emulsifying agents

- Added stabilizing component

\section{Emulsifying equipment:}

The primary emulsion can be prepared using a laboratory mixer or homogenizer to provide a good dispersion of droplets within the appropriate continuous phase ${ }^{13,14}$. The secondary emulsification stage must disperse the primary emulsion into droplets of suitable size for use in delivery vehicles Excessive mixing, especially at high shear, can cause the primary emulsion droplets to rupture. Lowspeed, low-shear mixers should be used, or the system can be shaken by hand. Ultrasonic homogenizers must be used with care for the secondary emulsification step.

\section{Nature of the aqueous phase:}

The aqueous phase is the dispersed phase in a w/o emulsion and a continuous phase in a w/o/w emulsion. Internal aqueous phase are often solution of encapsulated compound, such as sugar, salt and nutrient ${ }^{15}$. External aqueous phase are solutions of emulsifiers e.g. proteins and stabilizers e.g. polysaccharide. The volume fraction of the aqueous phase has large effect on stability of double emulsion.

\section{Nature of the oil phase:}

The oil phase to be employed in a pharmaceutical emulsion must be nontoxic and it also determines the encapsulation efficiency of emulsion. Vegetable oils usually have higher viscosity and higher solubility than mineral oil. Emulsion made from vegetable oil require a higher energy input and the resulting emulsion is less stable to the migration of water in and out of the internal aqueous phase. However high hydrophobicity materials such as mineral oils or hydrocarbon solvents are commonly used as the oil phase in studies of w/o or w/o/w emulsion. The various oils of vegetable origin (soybean oil, corn oil, sesame, peanut, safflower, etc.) are acceptable if purified correctly. Refined hydrocarbons such as light liquid paraffin squalene, as well as esters of fatty acids (ethyl oleate and isopropyl myristate) have also been used in double emulsions ${ }^{16}$. Oils derived from vegetable sources are biodegradable, whereas those based on mineral oils are only removed from the body very slowly. The order of decreasing stability and percentage entrapment has been found to be light liquid paraffin > squalene $>$ sesame oil $>$ maize or peanut oil ${ }^{14}$.

\section{Volumes of the phases:}

The quantity of water dispersed in the initial w/o emulsion [expressed as a phase volume ratio, $(\mathrm{w} / \mathrm{o} / \mathrm{w})$ ] can have an influence on both the yield and stability of the final emulsion system.

\section{Nature and quantity of emulsifying agents:}

Two different emulsifier (lipophilic and hydrophilic) are required to form a stable emulsion. In general, for a w/o/w emulsion the optimal HLB value will be in the range 2-7 for the primary surfactant and in the range 6-16 for the secondary surfactant. The concentration of the emulsifiers can also be varied. Too little emulsifier may result in unstable system, whereas too much emulsifier may lead to toxic effect and can even cause destabilization ${ }^{17}$.

\section{Added stabilizing components:}

The stabilizer are added for improve the stability of multiple emulsion. These include gelling or viscosity increasing agents added to the internal or external aqueous phases (e.g. $20 \%$ gelatin $^{18}$, methylcellulose and similar thickening agents ,as well as complexing agent that will lead to liquid crystalline phase at the $\mathrm{O} / \mathrm{W}$ interface (e.g. cetyl alcohol) and gelling agent or the oil phase (e.g. aluminium monostearate $)^{13}$.

\section{PREPARATION OF SDEDDS:}

SDEDDS emulsions are best prepared by reemulsification of primary emulsion. The following are the method of multiple emulsions:

\section{Two Steps Emulsification (Double Emulsification)}

2. Phase Inversion Technique (One Step Technique)

3. Membrane Emulsification Technique

\section{Two Steps Emulsification (Double Emulsification) 19, 20 :}

Two steps emulsification methods involve reemulsification of primary $\mathrm{W} / \mathrm{O}$ or $\mathrm{O} / \mathrm{W}$ emulsion using a suitable emulsifier agent. The first step involves, obtaining an ordinary $\mathrm{W} / \mathrm{O}$ or $\mathrm{O} / \mathrm{W}$ primary emulsion wherein an appropriate emulsifier system is utilized. In the second step, the freshly prepared W/O or O/W primary emulsion is re-emulsified with an excess of aqueous phase or oil phase. The finally prepared emulsion could be $\mathrm{W} / \mathrm{O} / \mathrm{W}$ or $\mathrm{O} / \mathrm{W} / \mathrm{O}$ respectively.

\section{Phase Inversion Technique (One Step Technique) ${ }^{21}$, 22.}

An increase in volume concentration of dispersed phase may cause an increase in the phase volume ratio, which subsequently leads the formation of multiple emulsions. The method typically involves the addition of an aqueous phase contains the hydrophilic emulsifier [Tween 80/ sodium dodecyl sulphate (SDS) or Cetyl trimethyl ammonium salt CTAB)] to an oil phase consisted of liquid paraffin and containing lipophilic emulsifier (Span80). A well-defined volume of oil phase is placed in a vessel of pin mixer. An aqueous solution of emulsifier is then introduced successively to the oil phase in the vessel at a rate of $5 \mathrm{ml} / \mathrm{min}$, while the pin mixer rotates steadily at 88 $\mathrm{rpm}$ at room temperature. When volume fraction of the aqueous solution of hydrophilic emulsifier exceeds 0.7 , the continuous oil phase is substituted by the aqueous phase containing a number of the vesicular globules among the simple oil droplets, leading to phase inversion and formation of $\mathrm{W} / \mathrm{O} / \mathrm{W}$ multiple emulsion.

\section{Membrane Emulsification Technique ${ }^{23}$ :}

In this method, a W/O emulsion (a dispersed phase) is extruded into an external aqueous phase (a continuous phase) with a constant pressure through a Porous Glass Membrane, which should have controlled and ISSN: 2250-1177 CODEN (USA): JDDTAO 
homogenous pores. The particle size of the resulting emulsion can be controlled with proper selection of Porous Glass Membrane as the droplet size depends upon the pore size of the droplet size depends upon the pore size of the membrane. The relation between membrane pore size and particle size of $\mathrm{W} / \mathrm{O} / \mathrm{W}$ emulsion exhibits good correlation as described by the following equation:

$$
Y=5.03 X+0.19
$$

Where $\mathrm{X}$ is the pore size and $\mathrm{Y}$ is the mean particle size of the multiple prepared using membrane emulsifier technique.

\section{CHARACTERIZATION FORMULATIONS:}

OF

SDEDDS

\section{Viscosity analysis of SDEDDS formulations}

The rheological measurements of the formulations cam be performed with a programmable rheometer, (Brookfield viscometer) operating with cone plate geometry (cone diameter $60 \mathrm{~mm}$, angle $1 \circ$, and gap $0.058 \mathrm{~mm}$ ). Samples transferred to the instrument and allowed to equilibrate to $25 \pm 1{ }^{\circ} \mathrm{C}$ for $10 \mathrm{~min}$ prior to the measurement. The apparent viscosity can be measured over a shear rate range of $0.1-300 \mathrm{~s}-1$. Viscosities (mPa s) of each formulation were measured at different shear rates; the mean constant shear viscosity may be determined from the data obtained at $300 \mathrm{~s}-1$. Six replicate analyses may be presented as means $\pm \mathrm{SD}$.

\section{2. pH determination}

The $\mathrm{pH}$ value of the freshly prepared emulsions and the emulsions kept at different conditions can be determined by a digital $\mathrm{pH}$-meter. $\mathrm{pH}$ measurements were repeated for multiple emulsions after 1, 3, 7, 14, 21 and 28 days of preparation, may be used for adjustments in formulation parameter $^{24}$.

\section{Microscopic tests}

Multiple emulsions have to be analyzed under the microscope to confirm the multiple characters. A drop of multiple emulsions have to be placed on the glass slide, diluted with water and covered by a glass cover. A drop of immersion oil placed on the cover slide and to be observed under the microscope.

\section{Entrapment efficiency}

The amount of drug entrapped is the amount of total drug minus the amount of free drug separated in the lower phase of the emulsion by centrifugation. The entrapped efficiency of the drug is defined as,

Efficiency of drug entrapped $(\%)=[(\mathrm{Td}-\mathrm{Fd}) / \mathrm{Td}] \mathrm{X} 100$

Where, $\mathrm{Td}=$ Total drug added, $\mathrm{Fd}=$ free drug present in the separated oil or aqueous phase ${ }^{25,26}$.

\section{Release of drug from SDEDDS formulations in vitro}

Release profiles from formulation filled in capsules have to be performed using the USP30 rotating paddle apparatus with $900 \mathrm{ml}$ of simulated gastric fluid (SGF, pH 1.2) without pepsin as the medium at $37 \pm 0.5{ }^{\circ} \mathrm{C}$. The speed of the paddle was adjusted to $75 \mathrm{rpm}$. Samples (5 $\mathrm{ml})$ are to be withdrawn and replaced with fresh media after 5, 15, 30, 60, 120, 240, 360 and $480 \mathrm{~min}$. Samples are filtered using a 0.45 micrometer filter and analyzed using an HPLC assay. Three replicate analyses are carried out for each formulation, and data presented as means \pm SD.

\section{Electrical conductivity tests}

Conductivity tests are performed for the multiple emulsions immediately after preparation and for the samples kept at different conditions by using digital conductivity-meter. Conductivity tests are repeated for the multiple emulsions after 1, 3, 7, 14, 21 and 28 days of preparation $^{27,28}$.

\section{Turbidity Measurement:}

This is to identify efficient self-emulsification by establishing whether the dispersion reaches Equilibrium rapidly and in a reproducible time. Nepheloturbidimetric evaluation is done to monitor the growth of emulsification. Fixed quantity of Self emulsifying system is added to fixed quantity of suitable medium $(0.1 \mathrm{~N}$ hydrochloric acid) under continuous stirring $(50 \mathrm{rpm})$ on magnetic plate at ambient temperature, and the increase in turbidity is measured using a turbidimeter ${ }^{29}$.

\section{Emulsion droplet size analysis:}

The droplet size distribution of double emulsions will influence the rheology, stability, color and test. These are generally measured by dynamic light scattering using a Malvern Particle Size Analyzers equipped with a $\mathrm{He}-\mathrm{Ne}$ laser. SDEDDS are mixed with distilled water $(200 \mathrm{ml})$ and stirred at mild agitation $(75 \mathrm{rpm})$ in a magnetic stirrer for $5 \mathrm{~min}$ at room temperature, forming the double emulsions. The particle size distribution of the double emulsions is determined after presentation. The refractive index of dispersed phase and continuous phase were calculated respectively, and the absorbance values of the emulsion droplets are calculated. The results are reported as the volume average diameter ${ }^{30}$.

\section{Stability studies:}

Stability tests can be performed at different storage conditions for both primary and multiple emulsions. The tests are performed on samples kept at $2 \pm 0.1{ }^{\circ} \mathrm{C}$ (in refrigerator), $25 \pm 0.1^{\circ} \mathrm{C} 60 \% \mathrm{RH}$ (relative humidity), $40 \pm$ $0.1{ }^{\circ} \mathrm{C}$ at $75 \%(\mathrm{RH})$ (in stability chamber) and $50^{\circ} \mathrm{c}$ in oven.

\section{In-vivo method:}

Male Wister rats are used and acclimatized for 7 days and fed the solid feed for 6 weeks. Weights of the rats serving as recipients of the $\mathrm{W} / \mathrm{O} / \mathrm{W}$ emulsions were $200-250 \mathrm{~g}$. Before feeding the sample solutions, the rats are fasted overnight for $17 \mathrm{~h}$. After being anesthetized with ether, blood samples are collected from the coccygeal vein 5 min before the administration using 23-27 gauge needles and used as the reference blood-sugar level at $0 \mathrm{~min}$. The sample solutions are fed at $50 \mathrm{IU} / \mathrm{kg}$-weight using feeding tubes. Purified water as a control solution, which contained insulin at the same concentration as the other emulsions, is also fed. The blood samples are collected at $15,30,45,60,120,180$, and $240 \mathrm{~min}$ from the coccygeal vein under temporary ether anesthesia. The blood concentrations in the samples can be measured by spectrophotometry or HPLC determination ${ }^{31}$. 


\section{PHARMACEUTICAL MULTIPLE EMULSIONS:}

1. They can mask the bitter taste and order of drug, e.g. chlorpromazine ${ }^{32}$.

2. Multiple emulsions are used in food $^{33}$.

3. They can be used to prolong the release of drug thereby providing sustained release action ${ }^{34,35}$.

4. Essential nutrients like carbohydrates, fats and vitamins can all be emulsified and can be administered to bed ridden patient as sterile intravenous injection.

5. Emulsion provides protection to drugs which are susceptible to oxidation or hydrolysis ${ }^{36,37}$.

6. Intravenous emulsions of contrast media have been developing to assist in diagnosis.

7. Increase in dosing interval.

8. Hydrophilic as well as hydrophobic drug can be entrapped.

\section{REFERENCES:}

1. Amidon, G.L., Lennernas, H., Shah, V.P., Crison, J.R., A theoretical basis for a biopharmaceutic drug classification: the correlation of in vitro drug product dissolution and in vivo bioavailability. Pharm. Res.1995, 12, 413-420.

2. Miyake, M., Oka, Y., Minami, T., Toguchi, H., Odomi, M., Ogawara, K., Higaki, K., Kimura, T., Combinatorial use of sodium laurate with taurine or 1-glutamine enhances colonic absorption of rebamipide, poorly absorbable antiulcer drug, without any serious histopathological mucosal damages. J. Pharm. Sci2003, 92, 911921.

3. Asada, H., Douen, T., Waki, M., Adachi, S., Fujita, T., Yamamoto, A., Muranishi, S., . Absorption characteristics of chemically modified-insulin derivatives with various fatty acids in the small and large intestine. J. Pharm. Sci. 1995, 84, 682-687.

4. Koga, K., Takarada, N., Takada, K.,. Nano-sized water-in-oil-inwater emulsion enhances intestinal absorption of calcein, a high solubility and low permeability compound. Eur. J. Pharm. Biopharm. 2010, 74, 223-232.

5. Shima, M., Tanaka, M., Fujii, T., Egawa, K., Kimura, Y., Adachi, S., Matsuno, R., Oral administration of insulin included in fine W/O/W emulsions to rats. Food Hydrocolloid 2006,20, 523-531.

6. Hanpramukkun $N^{*}$., Kongmuang S., Chansiri G 2009. The stability of clindamycin phosphate in w/o/w multiple emulsions. Int J Pharm Sci Tech 2009 Vol-3, Issue-2, 2009 ISSN: 0975-0525.

7. Yoshioka.T, lkeuchi.K, Hashida.M, Murashi. S and sezaki.H, chem. parrm. Bull, 1982;30:1408-1410.

8. Silva-Cunha, A., Grossiord, J.L., Seiller, M., Multiple Emulsions: Pharmaceutical Potentiality, in: Grossiord JL: Seiller M (eds.), Multiple Emulsions: Structure, Properties and Applications, Editions de Sante, France, 1999, pp 279-312,.

9. Taelman, M.C., Loll, P., Multiple emulsions in cosmetics. ICI Surfactants, Reprint, RP112/94E, 1994.

10. Omotosho, J.A., Whateley, T.L., Florence, A.T., Release of 5fluorouracil from intramuscular w/o/w multiple emulsions.Biopharm. Drug. Disp. 1989, 10: 257-268,.

11. Ohwaki.T, Nitta.K, Ozawa.H, Kawashimay. Y, Hino.T, Takechu, int. j. Pharm, 1992; 85:19-25.

12. Jager-Lezer, N., Denine, R., Grossiord, J.L., Wepierre, J., Rault, S., Seiller, M., Formulating multiple emulsions with moisturizing actives. Cosm. Toilet., 111: 53-58, 1996.

13. Florence AT, Whitehill D. The formulation and stability of multiple emulsions. Int J Pharm. 1982; 11:277.

14. Davis SS, Walker IM. Measurement of the yield of multiple emulsion droplets by a fluorescent tracer technique. Int J Pharm.1983; 17:203-213.

15. Garti, N. and Aserin, A. Pharmaceutical emulsion, double emulsion, microemulsion. In microencapsulation -Method and Industrial application. Ed. Benita, S. New York, Marcel Dekker: 1996b, 411 534.

16. Davis SS, Hadgraft J, Palin KJ. Encyclopedia of Emulsion Technology. Marcel Dekker. New York. 1985; 2:159.

17. Davis SS, Walker IM. Multiple Emulsions as Targetable Delivery Systems. Methods in enzymology . 1987; 14,951-64.

18. Yoshioka T,Ikeuchi K, Hashida M, Muranishi S,Sezaki H Prolonged release of bleomycin from parenteral gelatin spheres in oil-in water emulsion. Chem Pharma Bull.1982; 30:1408.

19. Dickinson, E and McClements, D , Water-in-oil-water multiple emulsion. In Advances in Food Colloids. Ed. Dickinson, E and
CONCLUSION:

From last 100 years, the only route available for the delivery of certain protein, peptide and anticancer drug is of injectable origin. The presentation of such highly soluble drugs via oral route has great commercial importance regarding the patient compliance, stability of product, the ease of formulation and manufacturing consideration. The present study will be an attempt to describe the role of oral route for systemic delivery of such highly water soluble (BCS Class-III) drugs. The investigation will provide the delivery of such drugs by utilizing the lymphatic system and also provide the means for delivery of highly water soluble, poorly permeable life saving drugs used in the disease like cancer, diabetes, vaccine etc. The evaluation of such products will definitely beneficial for the future delivery of such drugs.

McClements, D. J. Cambridge, UK, Blackie academic and professional:1996, 280-300.

20. Van der Graaf, S., Schroen, C. and Boom, R. Preparation of Double emulsion by membrane emulsification- a review. Journal of Membrane Science2005, 251:7-15.

21. Matsumoto, S., Koh, Y. and Michiura, A. Preparation of w/o/w emulsion in an edible form on the basis of phase inversion technique. Journal of Dispersion Science and Technology1985, 6(5):507-520

22. Matsumoto, S., and Kang, W. Formation and application of multiple emulsion. JDST, 1989,10(4 \& 5):455-482.

23. http://www.scribd.com/doc/24751787/Multiple-Emulsions

24. Lieberman HA, Martin R, Gilbert R, Banker S: Pharmaceutical Dosage Forms: Disperse system: Marcel Dekker: Volume II; 1994; p. 47-97, $261-310,183-239$.

25. Davis SS: The Emulsion: obsolete dosage form or novel drug delivery system and therapeutic agent. J. Clin. Pharm. 1976; 11-27.

26. U. S. pharmacopoeia: the official compendia of standards, USP 24, NF 19; Asian edition; 2000; p. 842-843.

27. Jim J, Diane B, Rheology and Stability of Water-in-Oil-in- Water Emulsions Containing Span 83 and Tween 80: AAPS Pharma. Science; 2003; 7.

28. Nielloud F, Marti-Mestres G, Laget JP, Fernandez C, Maillos H, Emulsion Formulations: Study of the influence of parameter with experimental designs. Drug Development and Industrial Pharmacy; 1996; 22(2), 159-166.

29. Balakrishnan P., Lee B.J., Oh D.H., Kim J.O., Hong M.J., Jee J.P., Kim J.A., Yoo B.K., Woo J.S., Yong C.S. and Choi H.G. Enhanced oral bioavailability of coenzyme Q10 by a novel solid selfemulsifying drug delivery system. Int J Pharm.2009, 374: 66-72.

30. Date A.A. and Nagarsenker M.S. Design and evaluation of selfnanoemulsifying drug delivery systems (SNEDDS) for cefpodoxime proxetil. Int J Pharm.2007, 329:166-172.

31. Motohiro Shima*, Miyono Tanaka, Takao Fujii, Kahori Egawa, Yukitaka Kimura, Shuji Adachi, Ryuichi Matsuno Oral administration of insulin included in fine $\mathrm{W} / \mathrm{O} / \mathrm{W}$ emulsions to rats Food Hydrocolloids2006, 20 523-531.

32. Khan AY. Potentials of Liquid Membrane System: An overview, Pharmainfo.net. 2007;5: Issue 6.

33. Rayner BM, Bergenstahl L, Massarelli G, Tragardh. Double emulsions prepared by membrane emulsification: stability and entrapment degree in a flavour release system in: Abstract Food Colloids Conference, Harrogate. 2004.

34. Okochi, H., Nakano, M., Basic studies on formulation, method of preparation and characterization of water-in-oil-in-water type multiple emulsions containing vancomycine. Chem. Pharm. Bull.1996, 44: 180-186.

35. Doucet, O., Ferrero, L., Garcia, N., Zastrow, L., O/W emulsion and w/o/w multiple emulsions: Physical characterization and skin pharmacokinetic comparison in the delivery process of caffeine. Int. J. Cosm. Sci.1998, 20: 283- 295.

36. Gallarate M, Cavalli R, Gagliardi E and Carlotti ME. On the use of saccharose esters as emulsifiers for W/O/W multiple emulsions containing ascorbic acid. Acta Technologiae et legis Medicamenti $1999 \mathrm{a} ; 10(1): 1-16$.

37. Gallarate M, Carlotti ME, Trotta M and Bovo S. On the stability of ascorbic acid in emulsified systems for topical and cosmetic use. Int J Pharm 1999b;188:233-241. 